Research Article

\title{
Research on the Preparation of Microbial Capsules by Epoxy Resin-Coated Bacillus pasteurii
}

\author{
Yingying Hu, ${ }^{1,2}$ Weitao Liu $\left(\mathbb{D},{ }^{1}\right.$ Xinlei Jia $\left(\mathbb{D},{ }^{2}\right.$ Lanjuan $\mathrm{Xu},{ }^{2}$ Jianjun Shen, ${ }^{2}$ \\ and Xiangming $\mathrm{Hu}^{1}$ \\ ${ }^{1}$ College of Safety and Environmental Engineering, Shandong University of Science and Technology, Qingdao 266590, China \\ ${ }^{2}$ Department of Chemical Engineering and Safety, Bin Zhou University, Bin Zhou 256600, China \\ Correspondence should be addressed to Weitao Liu; sdkdwtl@163.com
}

Received 2 September 2020; Accepted 30 October 2021; Published 25 November 2021

Academic Editor: Zhixiong Li

Copyright (C) 2021 Yingying Hu et al. This is an open access article distributed under the Creative Commons Attribution License, which permits unrestricted use, distribution, and reproduction in any medium, provided the original work is properly cited.

\begin{abstract}
With the increasing number of underground engineering construction projects such as coal mining, tunnel, and subway, water inrush disasters occur more and more frequently. Inspired by the phenomenon of microbial mineralization and diagenesis, microbial-induced calcium carbonate precipitation (MICP) is used to repair cracks in cement-based materials, which provides a new idea to solve the problem of water inrush. To investigate the self-healing properties of microbial capsules, this paper selected epoxy resin E-51 cured by DMP-30 as the wall material and Bacillus pasteurii as the core materials for experiments. In this paper, a single-factor method was adopted to determine the optimal preparation process of microbial capsules and the oil-phase separation method to prepare the microbial capsules. The effects of various factors on the experimental results under different core-wall ratios, reaction time, reaction temperatures, and agitation rates were analyzed. Microbial capsules were analyzed by Fourier transform infrared spectroscopy and optical microscopy to explore the functional groups and features of microbial capsules. The experimental results showed that the microbial capsules achieved the best performance with a core-to-wall ratio of $1: 3$, a reaction temperature of $50^{\circ} \mathrm{C}$, a reaction time of $40 \mathrm{~min}$, and a stirring rate of $300 \mathrm{rpm}$. Meanwhile, we determined the spore survival rate of microbial capsules and finally studied the waterproofness, storage stability, and rupture under the pressure of microbial capsules. We concluded that microbial capsules have high-efficiency and self-healing properties.
\end{abstract}

\section{Introduction}

In the underground engineering, microcracks often occur in concrete layer, which not only reduces the bearing capacity of the concrete structure but also affects its durability and waterproofness [1-8]. Currently, a more effective method for repairing concrete cracks is microcapsule technology. This technique involves coating the desired material with a suitable material to form a core-wall structure. The material used for coating is called a wall material, and the material to be coated is called a core material. The wall material is usually selected from organic polymer materials and inorganic materials, and the selection of the core material is determined according to the application of the microbial capsules. When microcapsule technology applies to the crack repair of concrete, its essence is the use of microorganisms to induce the formation of calcium carbonate. A specific microorganism is coated as a core material and embedded in concrete [9-13]. When the concrete cracks, the microbial capsule will break, and microbial metabolism will produce calcium carbonate, thereby repairing the crack.

At present, microcapsule technology has made some progresses in concrete repair. To improve cemented coral sand's self-healing efficiency, $\mathrm{Xu}$ et al. [14] fabricated the urea-formaldehyde (UF) microcapsule with in situ polymerization using controlled particles size distributions. They confirmed that the specimen's crack or compression triggered the microcapsules, which then reacted with the contribution from the healing agent to self-heal the internal cracks. Singh et al. [15] found that the crack healing capacity of the calcium lactate-prepared samples significantly improved, in spite that the expanded clay aggregates-based 
samples featured a considerable decrease in strength. Also, the use of Bacillus sp. bacterial solution in the concrete mix enhances its mechanical properties. Wang et al. [16] studied the physical properties of microcapsules and the microstructure of self-healing concrete. They also analyzed the influence of microcapsules on the strength, permeability, and long-term shrinkage of self-healing concrete. Al-Tabbaa et al. [17] focused on microcapsules, which contain a healing agent. This healing agent will be released upon crack propagation. Han et al. [18] pointed out that bacteria with expanded clay (EC) are very active in generating $\mathrm{CaCO}_{3}$. Liu [19] prepared a kind of microcapsule and manufactured a new type of self-healing asphalt. To do so, he mixed asphalt, microcapsule, and curing agent with proper ratio. Mohamed et al. [20] found that efficient self-healing capacity not only requires sufficient healing compounds (e.g., calcium acetate) but also demands a minimal number of bacterial spores. Tripathi et al. [21] studied the effect of microcapsule shell material on the mechanical behavior of self-healing epoxy composites. They encapsulated the liquid epoxy healant in melamine-formaldehyde (MF) and urea-formaldehyde (UF), using the emulsion polymerization technique to prepare microcapsules of different shell walls. Singh and Gupta [22] produced self-healing mortar by using alkaline bacteria producing minerals. Shahid et al. [23] focused on the microcracks' self-healing capability in concrete by using different Bacillus strains. They achieved a $16 \%$ increase in compressive strength in concrete and significant healing with Bacillus subtilis. Hu et al. [24-26] considered three novel types of healing agent encapsulation systems, namely, body-contact double capsule, parallel-style double capsule, and concentric-style capsule. They examined the compatibility of the PU healing agent with a dynamic crack using different accelerants. They also investigated the crack's adhesion area for different healing systems in terms of the capsule type, capsule spacing, accelerant, and crack width. Al-Ansari et al. [27] characterized the average diameter and shell thickness of the produced microcapsules. Souza and AlTabbaa [28] found that the aqueous core microcapsules presented a thicker shell which precluded the rupture upon crack. Cheng [29] researched into the epoxy resin microcapsules which contain both solid particles and cured epoxy resin. He finally obtained the thickness of the shell coated with alkali-resistant Bacillus $\mathrm{H}_{4}$.

Wang et al. [30, 31] used alginate as the wall material and successfully prepared microbial capsules by using Bacillus sphaericus fixed in hydrogel as the core material, thus effectively protecting the bacterial activity. Van Tittelboom et al. [32] adopted epoxy resin as the wall material and Bacillus coli as the core material to make spore bio-microbial capsules, which solved the problem of spore burial and dormancy in concrete. Cheng [33] prepared microbial capsules with ethyl cellulose and epoxy resin as the wall material, respectively, and Bacillus alkalisediminis $\mathrm{H}_{4}$ as the core material. The experimental results showed that microbial capsules have an excellent repair effect on concrete cracks $[34,35]$. There are still some issues in the existing research that require further in-depth research. Among them, one of the critical issues is how to reduce the preparation cost and efficiently utilize the material to prepare microbial capsules with the best biocompatibility and mechanical triggering performance.

This paper investigated the application of epoxy resin as a bacterial carrier in the self-repairing system of Bacillus pasteurii. First, we designed and successfully prepared $\mathrm{Ba}$ cillus pasteurianum microcapsules, optimized the microcapsule preparation process through experiments, and obtained the process parameters such as the core-wall ratios, reaction temperatures, reaction time, and agitation rate required to achieve the best performance. Next, we characterized the performance of the prepared microcapsules and studied the biocompatibility of epoxy resin and Bacillus pasteurii by measuring the spore survival rate of the microcapsules. In addition, the strength test of the prefabricated cracks in this paper confirms that the prepared microbial capsules have high-efficiency self-healing properties. The research results of this paper provide new ideas for studying a wider range of self-repairing bacterial carriers and improving the repair activity and strength repair rate of bacteria in harsh environments such as mines.

\section{Experiments and Materials}

2.1. Selection of Wall Materials. In the preparation of microbial capsules, in order to achieve the best results, the wall material needs to meet specific requirements. First, to prevent the core material from oxidizing and volatilizing during storage, the wall material needs to have good airtightness. Meanwhile, the wall material must have a specific mechanical strength to ensure the isolation and protection of the core material. The wall material also needs to have suitable brittleness to guarantee that the core material can be released typically when the triggering condition is reached.

On the other hand, in the preparation of microbial capsules, attention should be paid to the adverse effects of concrete conditions on microorganisms. In other words, we should prevent outside air, moisture, and oxygen from entering the microbial capsules to cause spores to germinate in advance. Furthermore, the wall material needs to be biocompatible and low in toxicity to maintain the activity of the core material.

Epoxy resin is not only dense, waterproof, and mechanically robust and brittle but also nontoxic and has excellent biocompatibility. Therefore, in all aspects, this paper chooses epoxy resin E-51 as the wall material.

Table 1 shows the experimental instruments. This paper utilized the ultraclean workbench and Chinese medicine pellet machine for the preparation of bacterial core material. Meanwhile, we used a digital constant temperature water bath and drying box to complete the wall material to cover the core material. We observed the microbial capsule's corewall structure with an optical microscope and the absorption peak in the infrared spectrum of the microbial capsule by Fourier transform infrared spectroscopy. Additionally, a television microscope was used to explore the waterproofness, storage stability, and rupture ability under the pressure of the microbial capsules. The survival rate of the spores was measured using the biochemistry incubators. 
TABLe 1: Experimental instruments.

\begin{tabular}{lcc}
\hline Experimental instruments & Model & Manufacturer \\
\hline Electronic balance & BSA223S & Sartorius Instrument Co., Ltd \\
Television microscope & SA3300 & Beijing Tech Instrument Co., Ltd \\
Digital constant speed electric mixer & JJ-1A & Jintan Hongye Experimental Instrument Factory \\
Digital constant temperature water bath & HH-1 & Changzhou Jintan Kexing Instrument Factory \\
Electric blast drying box & Model 101 & Beijing Ever Bright Medical Treatment Instrument Co., Ltd \\
Chinese medicine pellet machine & HBZ-201 & Ruian Hanbo Electromechanical Co., Ltd \\
Fourier transform infrared spectrometer & NICOLET380 & Thermo Nicolet Co., Ltd \\
Powder tablet press & PC-24 & Tianjin JingTuo Instrument Technology Co., Ltd \\
Biochemical incubator & HPX-80 & Shanghai Hengyue Medical Equipment Co., Ltd \\
\hline
\end{tabular}

2.2. Selection of Core Materials. The microbial capsule core must be a microorganism with life activity and mineralization. Microbial mineralization types fall into two types: microbial-controlled mineralization and microbial-induced mineralization. Microbial-controlled mineralization depends on the physiological processes of microorganisms and has nothing to do with changes in the external environment, while microbial-induced mineralization is produced by activities such as cell metabolism.

This research selects Bacillus pasteurii as the core microbe that adopts the microbially induced mineralization. More specifically, we make microbes into dry spore powder and mix the powder with the required nutrients and auxiliary materials such as microcrystalline cellulose to make core particles. Meanwhile, we induce calcium carbonate by cell metabolism to self-repair the concrete.

2.3. Measurement of Curing Agent Effect. To explore the effect of the curing agent, the epoxy resin E-51 was precured separately in advance with three curing agents: 2,4,6-trisphenol (DMP-30), m-xylylenediamine (MXDA), and silane coupling agent $(\mathrm{KH}-151)$. The amount of the curing agent MXDA is usually calculated based on the active hydrogen equivalent of the amine curing agent. Figure 1 illustrates the structural formula of MXDA.

The molecular weight of MXDA is 136.19, and the number of active hydrogens is four. Accordingly, its active hydrogen equivalent is 34.05 . The epoxy value of epoxy resin E-51 is 0.51, and the theoretical amount of MXDA is $17.37 \mathrm{~g}$ per $100 \mathrm{~g}$ of epoxy resin E-51. Its calculation formula is shown as follows:

$$
W=\frac{M}{N} \times E,
$$

where $W$ is the amount of curing agent required per $100 \mathrm{~g}$ of epoxy resin E-51, $M$ is the molecular weight of MXDA, $N$ is the number of active hydrogens of MXDA, and $E$ is the epoxy value of the epoxy resin.

The amounts of curing agents DMP-30 and $\mathrm{KH}-151$ were added according to empirical values. That is, the amount of DMP-30 is $10 \mathrm{~g}$ per $100 \mathrm{~g}$ of epoxy resin E-51, and the amount of $\mathrm{KH}-151$ is $15 \mathrm{~g}$.

In order to determine the curing effect, we placed $20 \mathrm{~g}$ of epoxy resin E-51 in a $50^{\circ} \mathrm{C}$ water bath for 10 minutes, diluted, and added with a curing agent. The bubbles were uniformly discharged after we stirred it, and we then placed it in a water

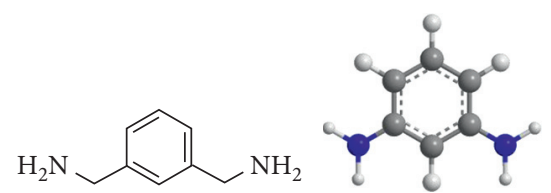

FIgURE 1: The structure formula of MXDA.

bath for heat preservation. Afterward, we placed it in a beaker and observed the curing phenomenon. Table 2 shows the control experiments.

\subsection{Microbial Capsule Preparation}

2.4.1. Core Material Preparation. The microcapsule core material is prepared by mixing dry spore powder, auxiliary materials, and nutrients and then granulating by a granulation apparatus that is shown in Figure 2. The specific preparation method is as follows:

Step 1. Mixing stage: Weigh nutrients according to the proportion of the medium components of the optimized strains, i.e., weigh $1 \mathrm{~g}$ of urea, $0.25 \mathrm{~g}$ of soy peptone, $0.75 \mathrm{~g}$ of casein, and $0.25 \mathrm{~g}$ of sodium chloride. Add $50 \mathrm{~g}$ of microcrystalline cellulose for expanding the core volume and $1.5 \mathrm{~g}$ of hydroxypropyl methylcellulose to promote adhesion of microcrystalline cellulose to spores and nutrients.

Step 2. Grouping stage: Weigh $0.5 \mathrm{~g}$ of dry spore powder in a beaker and add $150 \mathrm{~g}$ of distilled water to stir. Add the liquid solution to the mixture and stir to form a paste.

Step 3. Granulation stage: Place the obtained paste from the previous step in the extrusion port of the Chinese medicine pelletizing machine and obtain a flat body after being extruded appropriately. Take out the flat body and place it at the mouth of the purlin to obtain a strip. The strips are separated into individual pieces and placed at the pellet opening to roll out the granules. Place the pellets in a rounder, take out, and dry in a lowtemperature drying oven at $40^{\circ} \mathrm{C}$ for 24 hours. Finally, we obtain core particles with single-particle size.

The flowchart of preparing the core material is shown in Figure 3. The nutrients contain urea, soy peptone, casein, and sodium chloride; and the auxiliary materials encompass microcrystalline cellulose and hydroxypropyl methylcellulose. 
TABle 2: Control experiments.

\begin{tabular}{lcccc}
\hline \multirow{2}{*}{ Number } & \multicolumn{3}{c}{ Experimental conditions } \\
& Curing agents & Water bath temperature ${ }^{\circ} \mathrm{C}$ & Duration of heat preservation min & Curing agent amount g \\
\hline 1 & DMP-30 & 50 & 10 & 2 \\
2 & MXDA & 50 & 10 & 3.5 \\
3 & KH-151 & 50 & 10 & 3 \\
4 & DMP-30 & 20 & 10 & 2 \\
5 & MXDA & 20 & 10 & 3.5 \\
6 & KH-151 & 20 & 10 & 3 \\
\hline
\end{tabular}

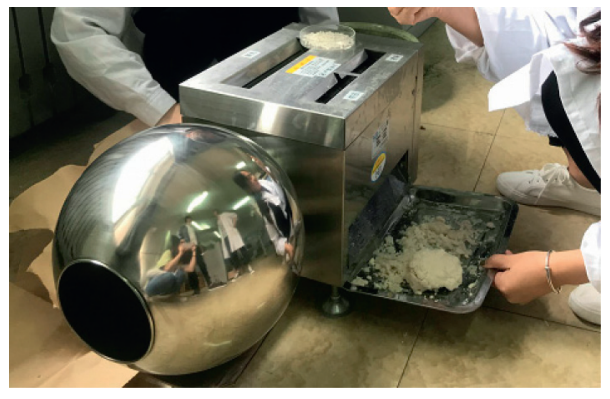

Figure 2: Core material granulation.

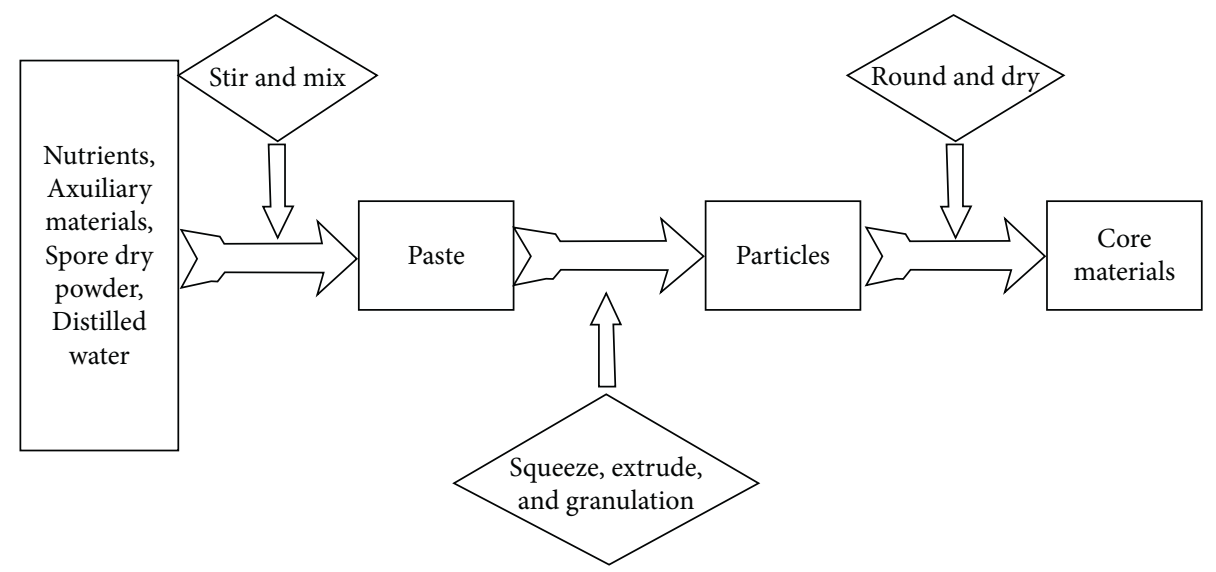

FIGURE 3: The flowchart of preparing the core materials.

2.4.2. Single-Factor Experiments Design. A variety of factors may affect the preparation of microbial capsules, such as reaction time, reaction temperature, core-wall ratio, and agitation rate. This experiment uses a single-factor experiment to determine the optimal preparation conditions for microbial capsules. Table 3 lists the experimental parameters.

2.4.3. Preparing the Microbial Capsule. We use the oil-phase isolation method to prepare microbial capsules, thus avoiding the contact of the core material with water during the preparation process, thereby maintaining the stability of the spores. Epoxy resin E-51 is a hydrophobic substance, which guarantees the feasibility of the experiment. The prepared core material particles were coated with epoxy resin E-51, and the epoxy resin E-51 was solidified on the surface of the core material to form a microbial capsule under the condition of a double oil phase. The specific preparation method is as follows:

Step 1. Mixing the wall and core materials: Weigh Epoxy resin E-51 and core particles according to a corewall ratio. Place both in a beaker and mix to mix well. Place the mixture in a constant temperature water bath and keep for $10 \mathrm{~min}$.

Step 2. Precuring stage: After $10 \mathrm{~min}$ of incubation, add the curing agent to the mixture, stir well, and place in a water bath for precuring for $30 \mathrm{~min}$.

Step 3. Film-forming stage: Add the mixture slowly to a three-necked flask, and set the reaction temperature and stirring speed. After 5 minutes, open the stopper on one side, slowly pour in the polydimethylsiloxane oil, and continue to stir for 1 hour. 
TABLE 3: Single-factor experiment parameters.

\begin{tabular}{lcccc}
\hline Number & & & Factors & \\
Core-wall ratio & Temperature ${ }^{\circ} \mathrm{C}$ & Reaction time & 40 & \\
\hline 1 & $1: 1$ & 50 & 40 & 300 \\
2 & $1: 2$ & 50 & 40 & 300 \\
3 & $1: 3$ & 50 & 40 & 300 \\
4 & $1: 4$ & 50 & 40 & 300 \\
5 & $1: 3$ & 40 & 40 & 300 \\
6 & $1: 3$ & 50 & 30 & 300 \\
7 & $1: 3$ & 60 & 40 & 300 \\
8 & $1: 3$ & 50 & 50 & 300 \\
9 & $1: 3$ & 50 & 40 & 300 \\
10 & $1: 3$ & 50 & 40 & 300 \\
12 & $1: 3$ & 50 & 40 & 350 \\
\hline
\end{tabular}

After the curing was completed, take out the final product, filter with absolute ethanol, and wash the surface of the polydimethylsiloxane. Place the product in a Petri dish and transfer to a low-temperature drying oven at $40^{\circ} \mathrm{C}$. As such, we obtain the microbial capsule. Figure 4 demonstrates the flowchart of the preparation.

\subsection{Features of the Microbial Capsules}

2.5.1. Waterproofness. Randomly select a plurality of microbial capsules in a beaker, slowly add distilled water to thoroughly soak the microbial capsules, and record the soaking time of the microbial capsules. Take 5-7 microbial capsules every other day, blot the surface moisture with absorbent paper, and place them on a glass slide. Place the slide under a microscope and adjust the magnification of the microscope to observe the presence or absence of cracks.

2.5.2. Storage Stability. Weigh specific amounts of microbial capsules in a Petri dish and place the Petri dish on a dry and ventilated bench. Record the initial weight of the microbial capsule and the weight of the microbial capsules on the 3rd, 6th, 9th, 12th, and 15th days. Observe the mass loss of the microbial capsules, and calculate the mass loss rate based on the following formula:

$$
M=\frac{m_{0}-m_{i}}{m_{0}} \times 100 \%,
$$

where $m_{0}$ and $m_{i}$ are the last and the current weight (g).

\subsubsection{Rupture Ability under Trigger Condition.} Randomly select plurality of microbial capsules, place them on a laboratory bench, and fracture them with tweezers. Place the fractured microbial capsules under a microscope, and fix the magnification to observe the rupture of the surface of the microbial capsule. In this way, we can judge whether the mechanical properties of the microbial capsules can be triggered and further germinate the microorganisms to conduct the self-repairing process when the concrete where they are buried ruptures.
2.5.4. Spore Survival Rate. We employ the plate colonycounting method to determine the spore survival rate of microbial capsules. First, ground the microbial capsule into a powder, add to the liquid medium, and shake well. Then, use a pipette to extract $1 \mathrm{ml}$ of the mixture, slowly inject into a tube containing $9 \mathrm{ml}$ of the liquid medium along the tube wall, and shake the tube to mix well. Repeat the above procedure and replace the sterile pipette once every dilution until it is diluted to $1 \times 10^{8}$ times.

Pipet $100 \mu \mathrm{L}$ of the diluted liquid, pour into a solid medium prepared in advance, and then uniformly distribute the colonies on the plate. After solidification, turn over the culture dish and place in an incubator for 24 hours. Observe the germination of the spores in the culture dish and count the number of colonies in the culture dish. It should be noted that at the dilution factor at this time, one colony represents one spore in the microbial capsule. The spore germination rate is obtained according to the number of colonies at the dilution factor and the number of spores in the core material.

\subsection{Verification of Self-Healing Effect of Microbial Capsules}

2.6.1. Test Pieces Preparation. Table 4 lists the specific mixing ratio of the experimental test pieces. Figure 5 shows the preparation of self-healing test piece. We designed three sets of control experiments. Specifically, Group A is a standard test piece without adding any repair agent. Group $B$ only adds the core material part from the repair agent, that is, the bacterial body. Group $\mathrm{C}$ adds the complete microbial capsule. Meanwhile, the cement mortar has a water-cement ratio of 0.3. The amount of the repair agent is $3.0 \%$ of the amount of the cementing material. Besides, the mold uses a cylindrical test piece with $\varphi$ of $50 \mathrm{~mm}$ and $\mathrm{H}$ of $100 \mathrm{~mm}$.

The specific preparation steps are as follows:

(1) Weigh the required materials according to the required amount, add cement, sand, and water in sequence, mix well, and finally add the microcapsules and mix well. 


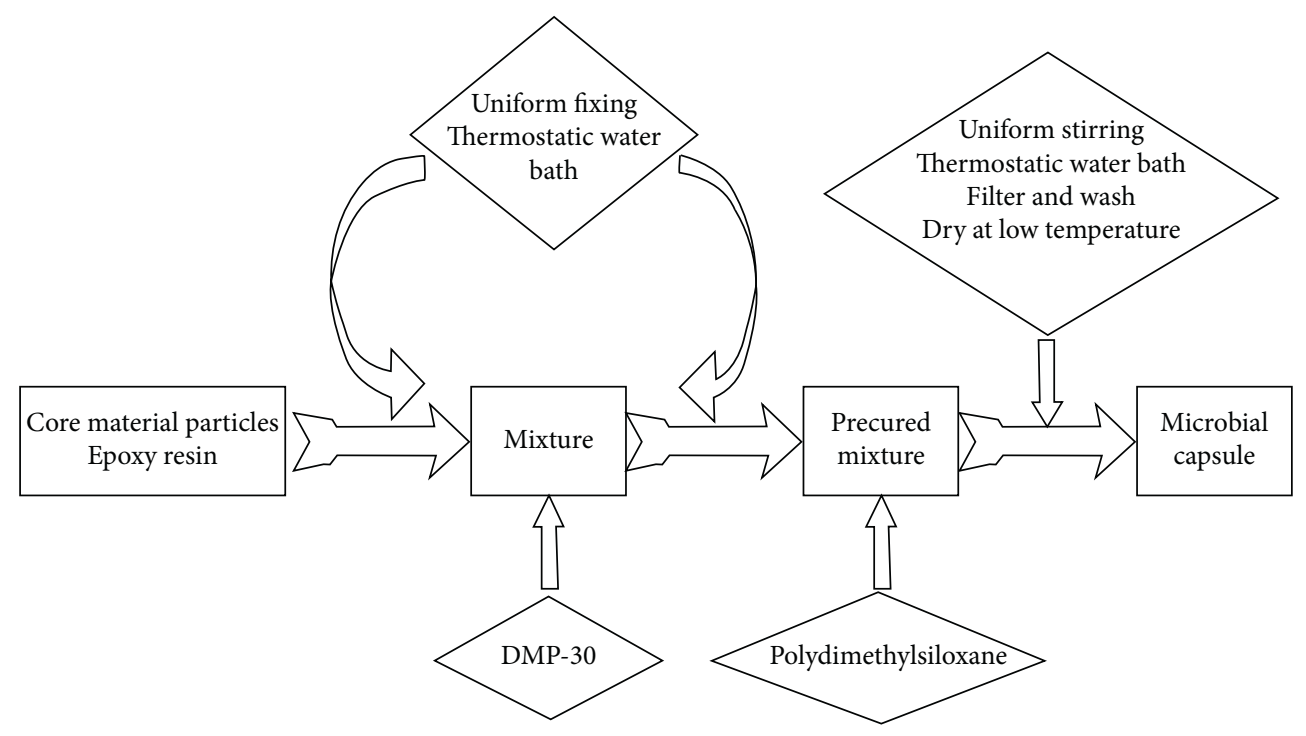

Figure 4: The preparing flowchart.

TABle 4: Material ratios.

\begin{tabular}{lcccc}
\hline Groups & Cement $(\mathrm{g})$ & Sand $(\mathrm{g})$ & Water $(\mathrm{g})$ & Repair agent \\
\hline 1 & 270 & 810 & 270 & N/A \\
2 & 270 & 810 & 270 & Bacterial body \\
3 & 270 & 810 & 270 & Microbial capsule \\
\hline
\end{tabular}
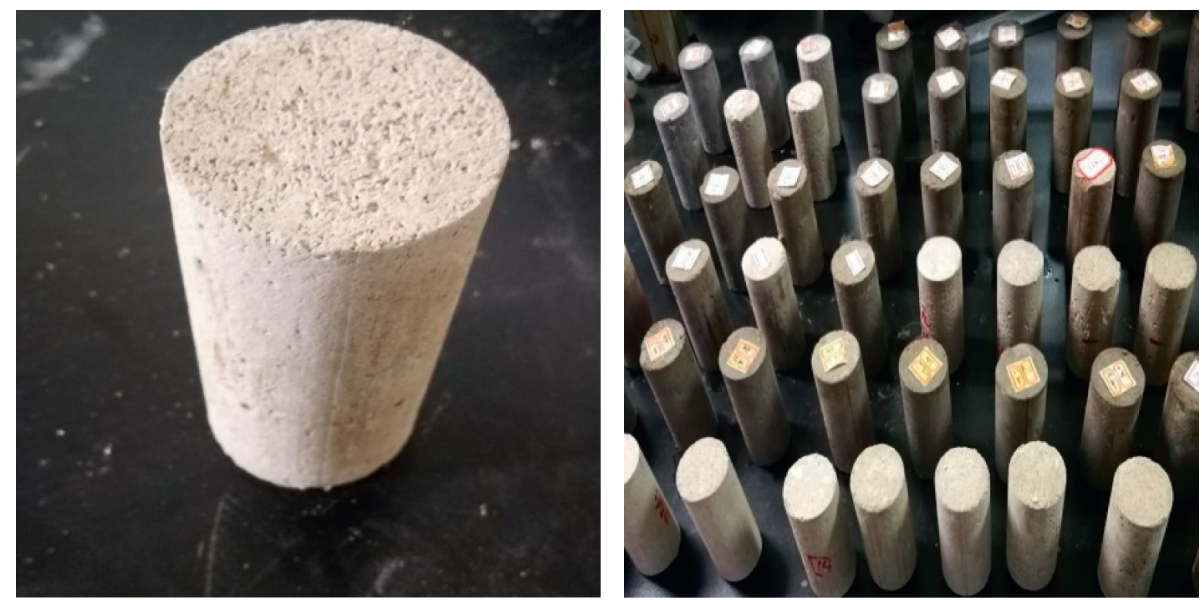

FIgURE 5: Preparation of self-healing testing pieces.

(2) Brush a layer of grease on the inside of the mold, pour the evenly mixed mixture into the mold, and shake it up.

(3) After leaving the mixture at room temperature for one day, demold. Then, put it in a standard constant temperature and humidity curing box (temperature $25^{\circ} \mathrm{C}$; air humidity $90 \%$ ), and stay until a specific time.

2.6.2. Prefabricating Crack for Test Pieces. This paper took the cement mortar test pieces within the curing period and manually prefabricated cracks. Based on a comprehensive analysis of various prefabricated cracking methods, this paper adopted a universal pressure testing machine to prefabricate cracks for cylindrical specimens, as shown in Figure 6. The specific steps are as follows:

(1) Place the test piece in the center of the pressurebearing plate of the testing machine, and adjust the bottom disc to a balanced state.

(2) Apply the axial stress at a displacement speed of $0.01 \mathrm{~mm} / \mathrm{min}$, and prefabricate the crack using a concentrated load in the center. 

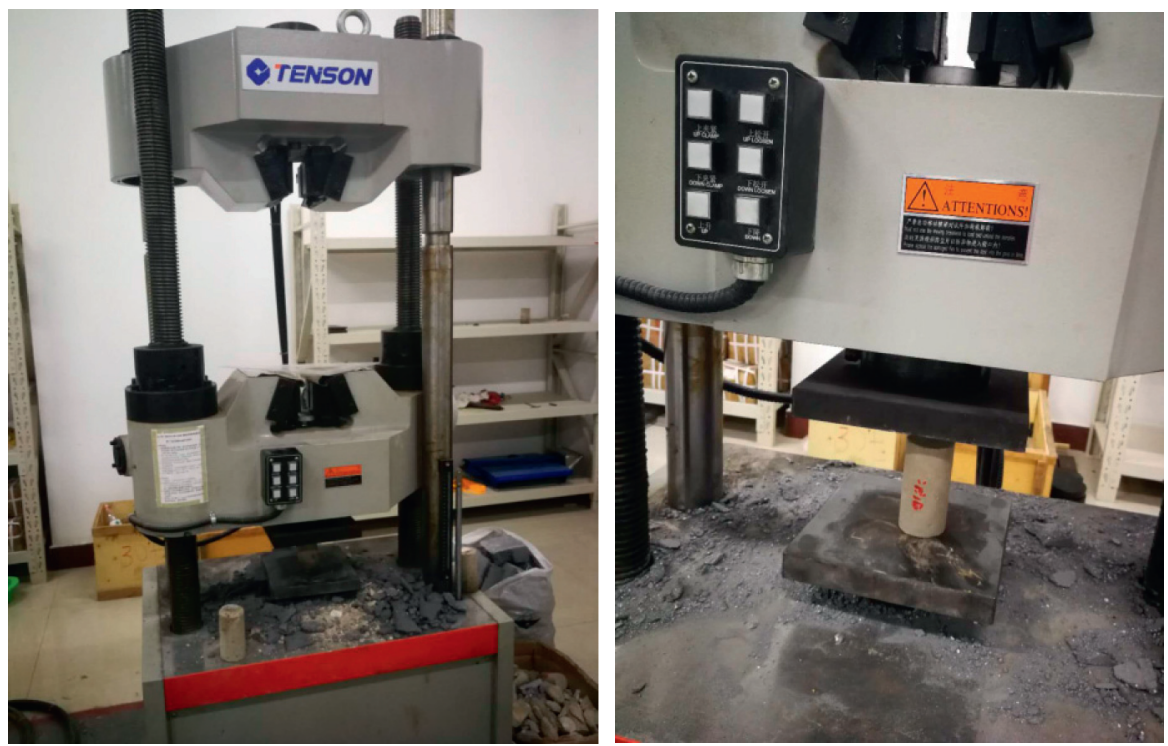

FIgURE 6: Microcomputer-controlled electro-hydraulic servo universal testing machine.

(3) When the obvious cracking sound occurs, stop the pressurization. By then, we can obtain a striped crack that diverges from the center of the test piece to the surroundings.

(4) Record the failure load and calculate the compressive strength according to the following formula:

$$
f=\frac{F}{A},
$$

where $f$ is the compressive strength of cubes of similar rock text pieces $(\mathrm{MPa}) ; F$ is the failure load of the test piece $(\mathrm{N}) ; A$ is the pressure area of the test piece $\left(\mathrm{mm}^{2}\right)$.

(5) Record the stress-strain curve and the test forcedeformation curve, and analyze the uniaxial compression curve of the test piece.

2.6.3. Curing of Test Pieces. During the self-repair experiment, there is an exchange of substances and energy, which demands the participation of microorganisms embedded in the test piece in advance. This process requires an effective medium to assist in energy exchange and material transportation. This test used the water curing method. Specifically, the cracked test pieces were immersed in the tap water, the cracked surface and the liquid surface were kept vertical, and the water temperature was adjusted to $25^{\circ} \mathrm{C}$.

2.6.4. Assessment of Self-Healing Performance. To evaluate the self-healing performance, we first conducted a water absorption test. The water absorption rate of the test pieces can reflect the weathering resistance and frost resistance. The water absorption rate depends on the number, size, and degree of cracks contained in the test piece. Water absorption can effectively reflect the degree of development of cracks and voids in the text pieces, so it is an important indicator to evaluate the nature of the test pieces. The steps for testing the water absorption of cement mortar test pieces are as follows:

(1) Set the temperature of the drying box to $75^{\circ} \mathrm{C}$, and after drying for $48 \mathrm{~h}$, weigh its dry weight marking as $m_{0}$

(2) Place the test piece into the sink, and the bottom is cushioned with a cuboid test block of $40 \mathrm{~mm} \times 40 \mathrm{~mm} \times 160 \mathrm{~mm}$

(3) Add water to the tank to $20 \mathrm{~mm}$, and maintain a constant water temperature and 90\% humidity

(4) Take the test piece out after immersion for $48 \mathrm{~h}$, wipe the moisture on the surface with a wrung-out wet cloth, and weigh its wet weight marking as $m_{1}$

(5) Calculate the water absorption rate of the test piece using $W=\left(m_{1}-m_{0}\right) / m_{0}$

Additionally, we conducted a uniaxial compression test. The compressive test is carried out on the test pieces after a specified time period, and the compressive strength of the specimens is obtained according to the following formula:

$$
\eta_{\text {STR }}=100 \times \frac{f_{\text {healed }}}{f_{\text {initial }}},
$$

where $\eta_{\text {STR }}$ is the strength repair rate (\%); $f_{\text {healed }}$ is the compressive strength after curing $(\mathrm{Pa})$; and $f_{\text {initial }}$ is the compressive strength without curing $(\mathrm{Pa})$.

\section{Results and Discussion}

3.1. Curing Effects of the Wall Material. Precuring of epoxy resin E-51 was carried out according to a control experiment (Table 3). The experiment shows that the curing reaction accelerates with the increase in the temperature of the water bath; and when the temperature of the water bath reaches $50^{\circ} \mathrm{C}$, the curing reaction is the fastest. 
Under the same conditions, changing the curing agent, we found that the curing agent DMP-30 can completely cure the epoxy resin E-51 after 30 minutes. In contrast, the time required for the curing agent MXDA to fully cure the epoxy resin E-51 was about two hours, while the $\mathrm{KH}-151$ did not have a curing effect on the epoxy resin E-51. Table 5 shows the properties of the cured product.

From the comparison of the physical properties of the cured products and the curing reaction time, it is concluded that the curing agent DMP-30 has the best curing effect. Moreover, the spore survival rate and mechanical triggering performance of DMP-30 prepared microbial capsules are the best.

3.2. Preparation of the Core Material. The spore dry powder, auxiliary materials, and nutrients are uniformly mixed, and the core material particles required for the experiment are obtained by stripping, extruding, pelletizing, and rounding, as shown in Figure 7. Figure 7(a) shows that the prepared core material particles are pure white before dried, have a large particle size, and are easily crushed by pressing. Figure 7 (b) shows that the particle size of the prepared core material is significantly reduced after drying. This is because the added microcrystalline cellulose and HPMC have good water swell ability.

The color of the core material particles changes from white to pale yellow due to the residual suspension in the added spore dry powder (as shown in Figure 8). Currently, the texture of the core material particles is hard, and the pressing does not break, which ensures the integrity of the core material particles in the process of preparing the microbial capsule.

\subsection{Impact of Single Factor on Microbial Capsule Preparation}

3.3.1. Reaction Temperature. The temperature can change the viscosity of Epoxy E-51. Specifically, as the reaction temperature increases, the viscosity gradually decreases. At the same time, different curing agents require different curing temperatures, and the properties of the cured products formed are also different. Epoxy resins cure at low temperature, and it has the best overall performance.

The results of single-factor experiments showed that the epoxy resin coated on the surface of the microbial capsule became more slippery, and the wall became thicker as the reaction temperature increased. However, when the experimental temperature reached $60^{\circ} \mathrm{C}$, the precured mixture appeared to unite in the three-necked flask, and the microbial capsules showed agglomeration. Since the activity of the Bacillus pasteurii used in the core material is not suitable for excessively high temperature, the optimum temperature for the experiment is $50^{\circ} \mathrm{C}$.

3.3.2. Reaction Time. In order to explore the effect of reaction time on the experiment, we keep the other factors unchanged and only change the reaction time to experiment. The experimental results show that the influence of reaction time on the preparation of microbial capsules is like the reaction temperature. That is, when the reaction time gradually increases, the coating effect on the surface of the core material is getting better and better, and the thickness of the wall material also gradually increases. Similarly, the precured mixture also exhibits agglomeration. The experimental results reveal that the optimal reaction time is $40 \mathrm{~min}$.

3.3.3. Core-Wall Ratio. Among the influencing factors of microbial capsules, the influence of core-wall ratio is the most significant. The core-wall plays an essential role in the wall thickness and particle size of the microbial capsule, thereby affecting its waterproof performance. This is because the difference in core-wall content directly affects the content of the wall material coated on the surface of the core material. In this experiment, the core-to-wall ratio was set to $1: 1,1: 2,1: 3$, and $1: 4$, respectively, to explore the effect of this factor on the experimental results.

In the experiment, we prepared microbial capsules according to different core-wall ratios to observe changes in wall thickness values. The experimental results are shown in Figure 9. The thickness of the wall material gradually increases as the core-wall ratio decreases, but when the core-wall ratio is greater than $1: 3$, the thickness increase of the wall material begins to decrease. This is because, at the lower core-wall ratio, the wall material content is higher than the core material content, the more the wall material can be coated by the core material, the thicker the wall material thickness. However, when the core-wall ratio reaches a specific value, the increase in the thickness of the wall material will slow down. In other words, the wall material content has begun to generate a residual amount concerning the core material content, and the utilization rate of the wall material starts to decrease. Considering the thickness of the wall material and its utilization, we set the optimum wall-core ratio as $3: 1$.

3.3.4. Agitation Rate. We prepared microbial capsules at an agitation rate of $250 \mathrm{rpm}, 300 \mathrm{rpm}$, and $350 \mathrm{rpm}$, respectively. From the prepared microbial capsules, we found that the thickness of the microbial capsule wall material decreased with the gradual increase in the rotational speed until it approached the particle size of the core material particles. This is because as the rotational speed increases, the shear stress of the agitator is higher than the viscous force of the epoxy resin so that the epoxy resin coated on the surface of the core material is peeled off under high-speed rotation. Meanwhile, under high-speed rotation, some core material particles are broken, which is not conducive to the survival of Bacillus pasteurii. Taken together, we set the best experimental speed as $300 \mathrm{rpm}$.

\subsection{The Structure Feature of the Microbial Capsule}

3.4.1. Structure Feature. Figure 10 illustrates a microbial capsule under an optical microscope. Figure $10(\mathrm{a})$ is a full picture of the microbial capsule. The core is oval in the 
TABLE 5: The properties of the cured products under various curing agents.

\begin{tabular}{lccc}
\hline Number & Curing agent & Amount of curing agent $(\mathrm{g})$ & Curing products properties \\
\hline 1 & DMP-30 & 2 & Orange, fragile \\
2 & MXDA & 3.5 & Light yellow, a little fragile \\
3 & KH-151 & 3 & Transparent, no curing effect \\
\hline
\end{tabular}
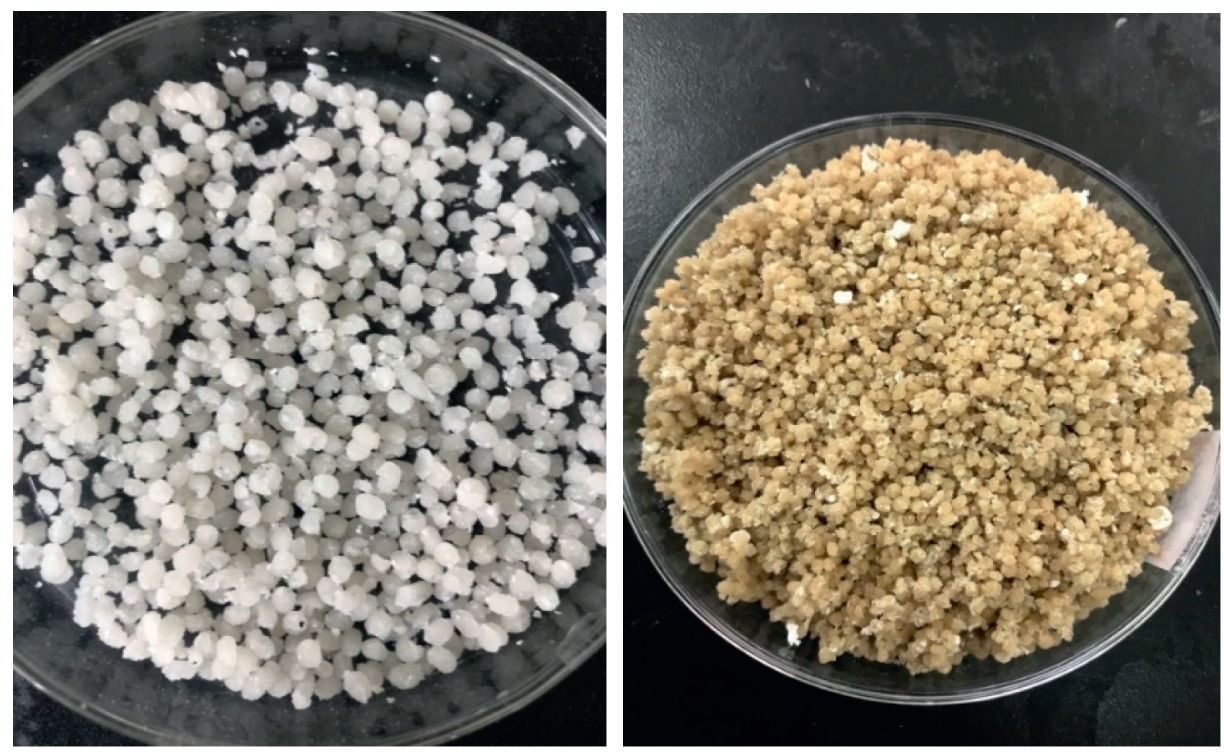

Figure 7: Particles of the core material: (a) particles before dried; (b) particles after dried.

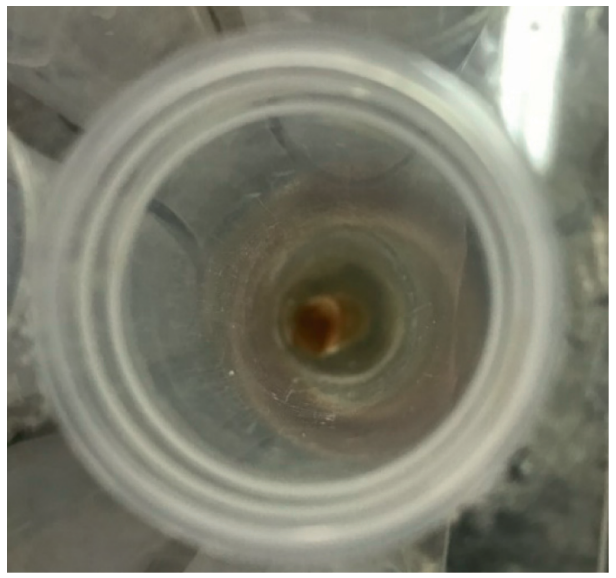

FIGURE 8: Dried spore powder after centrifugation and drying.

center, and the core material is epoxy E-51. Figure 10(b) is a partial view of the microbial capsule, i.e., the core-wall structure of the microbial capsule. As can be seen from the picture, the surface of the core material particles is rough, entirely covered by the solidified epoxy resin of the wall material. Meanwhile, the inside is crystallized, and the surface of the wall material of the microbial capsule is slightly smooth and flat.

3.4.2. Fourier Transform Infrared Spectroscopy. Use the Fourier transform infrared spectrometer to characterize the chemical structure of the microbial capsules. Mix the dried microbial capsule sample with potassium bromide in proportion and uniformly place it in a mortar. Slowly ground until it is ground into a powder and place it in a tableting machine for tableting. Place the sheet in an experimental apparatus for scan and analysis.

The epoxy resin E-51 selected in this experiment belongs to bisphenol A type epoxy resin. This type of epoxy resin has an aromatic hydrocarbon structure, which produces a richer infrared spectrum. Figure 11 illustrates the FTIR spectrum of the microbial capsule. At $830 \mathrm{~cm}^{-1}$ and $915 \mathrm{~cm}^{-1}$, they are characteristic absorption peaks of epoxy resin E-51. Specifically, at $830 \mathrm{~cm}^{-1}$, it is the absorption band of two 


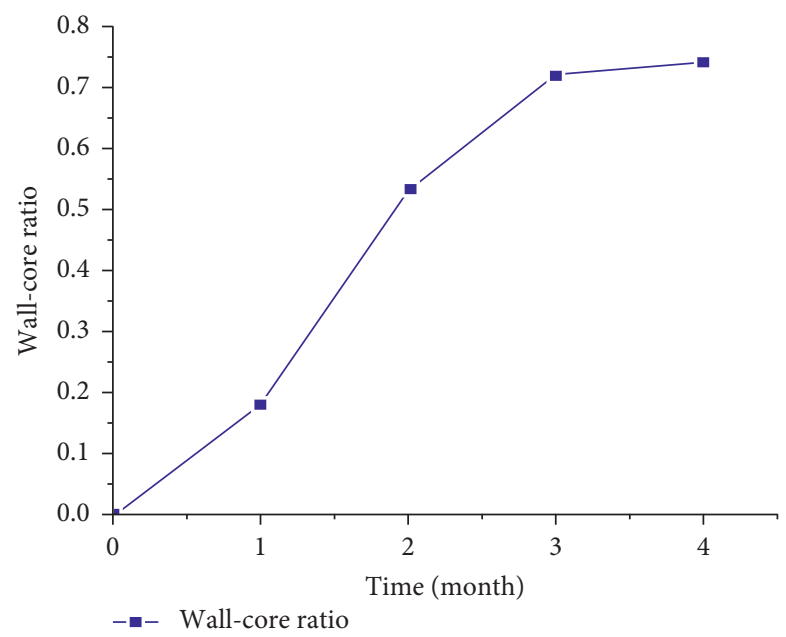

FIGURE 9: The trend of wall thickness with respect to various wall-core ratios.

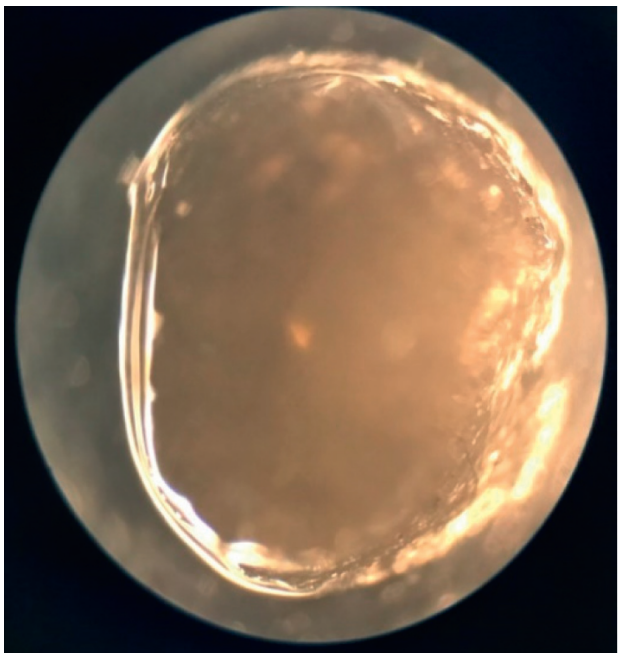

(a)

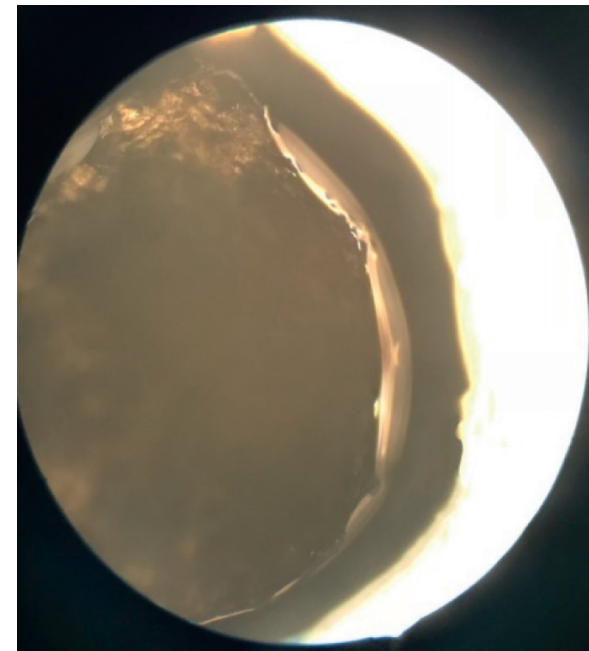

(b)

Figure 10: A microbial capsule under an optical microscope: (a) full picture of the microbial capsule; (b) partial view of the microbial capsule.

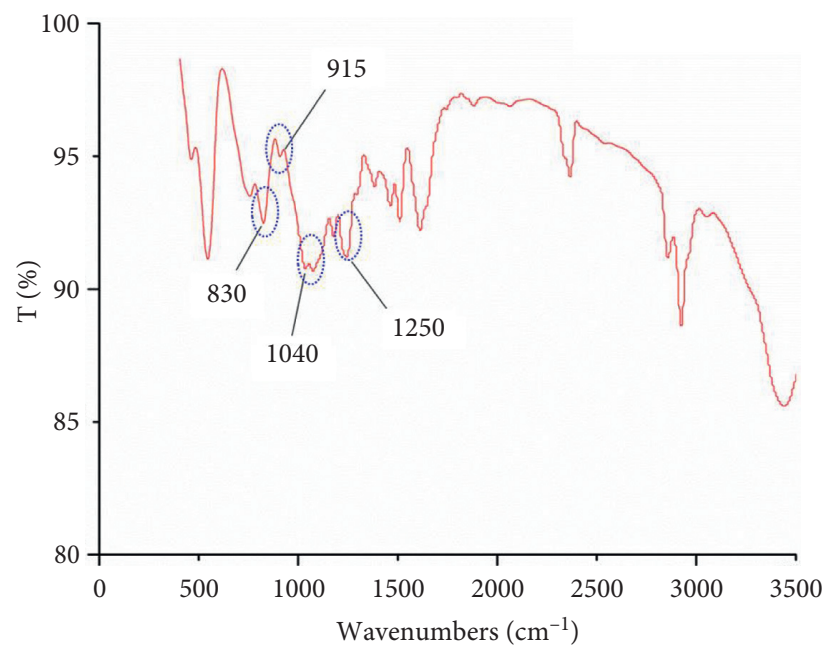

FIgURE 11: The FTIR spectrum of the microbial capsule. 
adjacent hydrogen atoms on the benzene ring; and at $915 \mathrm{~cm}^{-1}$, it belongs to the characteristic absorption band of the epoxy group. The characteristic peak produced by absorption of the aliphatic ether bond C-O-C appears at $1040 \mathrm{~cm}^{-1}$. The characteristic peak of phenyl ether occurs at $1250 \mathrm{~cm}^{-1}$.

\subsection{The Performance of Microbial Capsules}

3.5.1. Waterproofness. In the experiment, we chose microcrystalline cellulose to expand the volume of the core material and used hydroxypropyl methylcellulose as a binder to promote the fusion of dry spore powder, nutrients, and microcrystalline cellulose. These two substances are insoluble in water and have good water swell ability, and the volume of the core material expands after water absorption, thereby causing the wall material to rupture. Therefore, we can judge the waterproofness of the wall material according to this feature. We adopted an optical microscope to observe the surface of the microbial capsule, as shown in Figure 12. The figure clearly shows that the surface of the microbial capsule has no cracks, so the moisture does not penetrate the inside of the core material. In other words, the wall epoxy resin E-51 has excellent water resistance.

3.5.2. Storage Stability. Obtain $20 \mathrm{~g}$ of microbial capsules with single-particle size and weigh the mass on day 3, 6, 9, 12, 15, and 18. The results are shown in Table 6.

Figure 13 shows the quality of microbial capsules over time. As can be seen from the figure, the mass loss of the microbial capsule was significant in the first six days. As time goes by, the reduction of microbial capsule quality gradually stabilized, and the quality of microbial capsules did not decrease significantly in the later stage. This indicates that the microbial capsule will not drop after losing a small amount of mass, i.e., the microbial capsule has excellent storage stability.

3.5.3. Rupture Ability under Trigger Condition. Slowly fracture the microbial capsule with forceps and place it under an optical microscope for observation. Figure 14 displays an image of the ruptured portion under an optical microscope after the microcapsule breaks. Figure 14(a) shows the broken wall material after the microbial capsules are fractured, showing that the cracked part is smooth and transparent. Figure 14(b) reveals the core material after fracturing, showing an opaque black state, and the surface is not covered with a transparent ring. As can be seen from the figure, the core material and the wall material can be separated under pressure.

As described above, after the microcapsule capsule breaks, the core material and the wall material will separate. When the microbial capsule is buried in the concrete and the concrete cracks, the pressure is generated inside to cause the microcapsule to rupture and expose the core material. The core material is then in contact with moisture and oxygen to initiate germination, initiate cell metabolism, and produce calcium carbonate for self-healing.

3.5.4. Spore Survival Rate. Figure 15 illustrates the rupture of the microbial capsule under pressure after $24 \mathrm{~h}$ of incubation.

As can be seen from the figure, round white colony spots appear on the surface of the culture dish, and the number of colonies and diameters vary. After statistics, the average number of colonies per dish was 40 . That is, after $1 \times 10^{8}$ times dilution, the survival spores in the microbial capsule were $4 \times 10^{9} \mathrm{cfu} / \mathrm{ml}$.

According to the core-wall ratio, $4 \times 10^{9} \mathrm{cfu} / \mathrm{ml}$ was converted to $5.33 \times 109 \mathrm{cfu} / \mathrm{ml}$ of the spore survival per gram of core material in the microbial capsule. The spore survival per gram of the core material before preparation of the microbial capsule was $8 \times 10^{9} \mathrm{cfu} / \mathrm{ml}$. Thus, the spore survival rate in the microbial capsule was $66.7 \%$.

After the preparation of the core material and the microbial capsule, the Bacillus pasteurii remains active. The selected wall material has excellent biocompatibility with the spores, thus ensuring that the microbial capsule can be selfrepaired when being embedded in the concrete.

\subsection{Experimental Analysis of Self-Healing Performance}

3.6.1. Analysis of Water Absorption Test. In the mortar test piece, the calcium carbonate precipitate generated by microbial mineralization binds the sand particles and effectively fills the pores of the mortar test piece. Consequently, the porosity is reduced to a certain extent, and the water absorption of the test piece reduces accordingly. The change trend of water absorption of the test piece with time is shown in Figure 16.

As shown in the figure, with a fixed water-to-binder ratio, the water absorption rate of the cement mortar test pieces showed a downward trend with the extension of the curing age. This is due to the continuous increase in hydration products caused by microbial reactions, resulting in a tighter internal structure of the mortar. In addition, the addition of microbial capsules increased the water absorption of the mortar test piece, and the water absorption rate of the test piece showed an upward trend as the number of microbial capsules increased. Since the density of the microcapsules is relatively low, the density of the cement mortar test pieces also decreases with the increase in the microcapsule content, resulting in an increase in the internal porosity of the test pieces.

3.6.2. Analysis of Uniaxial Compression Test. Table 7 shows the compressive strength of the three groups of test pieces. The compressive strength of group A increased with the extension of maintenance age (48 days). The compressive strength of Group B was higher than that of standard test pieces in the initial stage of curing, but there was no significant change in the overall situation. When bacteria were added, the $\mathrm{CO}_{2}$ hydration reaction in the crack area was 

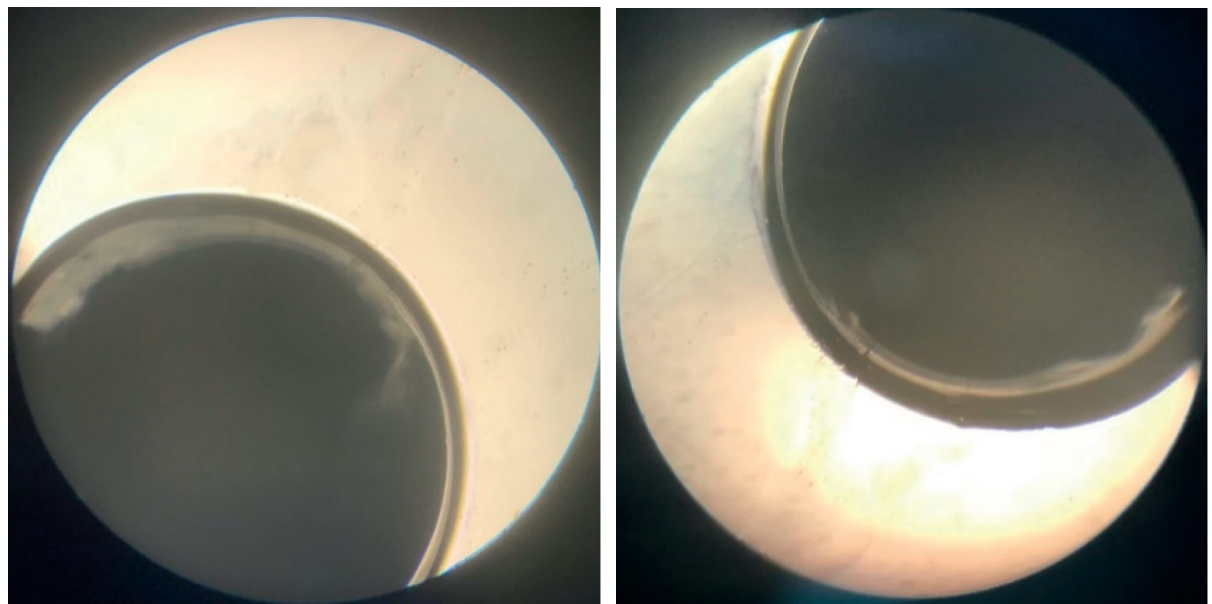

FIgURE 12: The waterproofness of microbial capsule.

TABLE 6: The measurement of stability of microbial capsule.

\begin{tabular}{|c|c|c|c|c|c|c|c|}
\hline \multirow{2}{*}{ Mass and loss } & \multicolumn{7}{|c|}{ Days } \\
\hline & Day 0 & Day 3 & Day 6 & Day 9 & Day 12 & Day 15 & Day 18 \\
\hline Mass & $20 \mathrm{~g}$ & $19.884 \mathrm{~g}$ & $19.797 \mathrm{~g}$ & $19.762 \mathrm{~g}$ & $19.753 \mathrm{~g}$ & $19.747 \mathrm{~g}$ & $19.740 \mathrm{~g}$ \\
\hline Mass loss & - & $0.6 \%$ & $0.4 \%$ & $0.17 \%$ & $0.04 \%$ & $0.03 \%$ & $0.03 \%$ \\
\hline
\end{tabular}

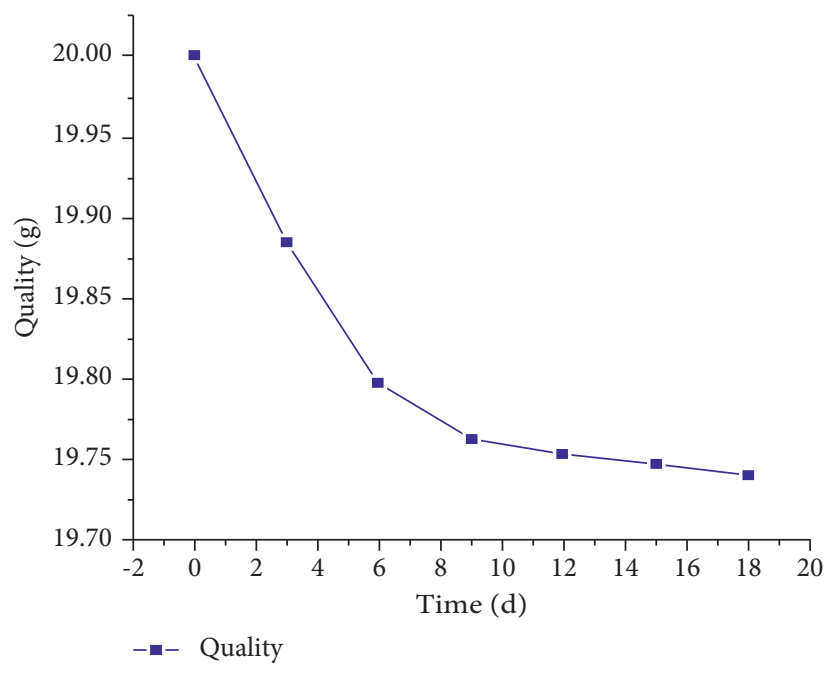

FIgURE 13: The mass trend of the microbial capsule.

accelerated. However, because the cement-based material is more alkaline and the bacteria have poor tolerance, the survival time inside the test pieces became shorter. With the increase in the curing time, few bacteria survived. To sum up, the compression resistance of Group C is significantly improved compared with that of the other two groups. Using epoxy resin as the wall material can achieve long-term survival of bacteria in cement-based materials. 


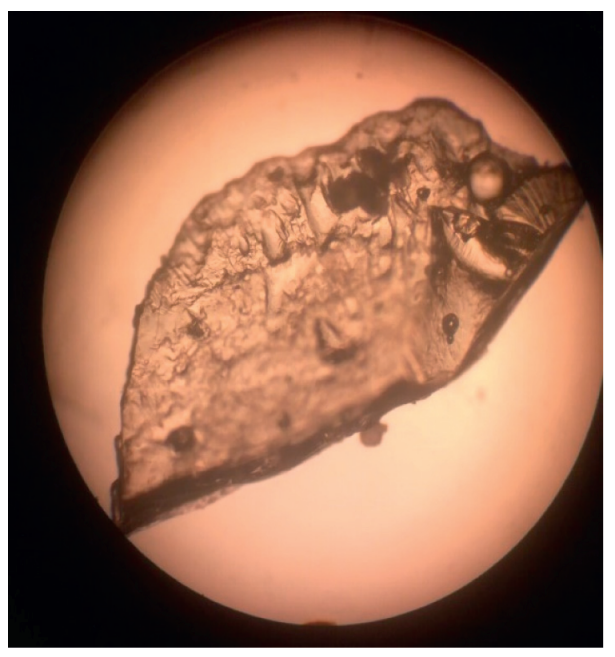

(a)

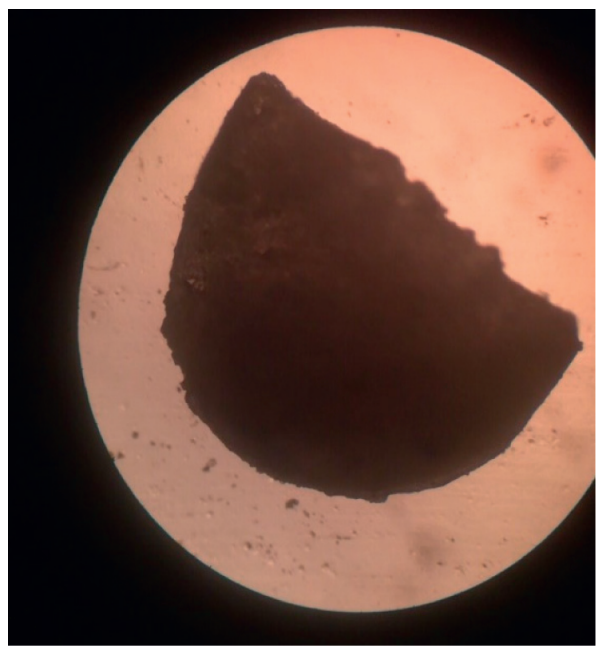

(b)

FIGURE 14: The fracture figure of the microbial capsule under pressure: (a) broken wall material; (b) core material.
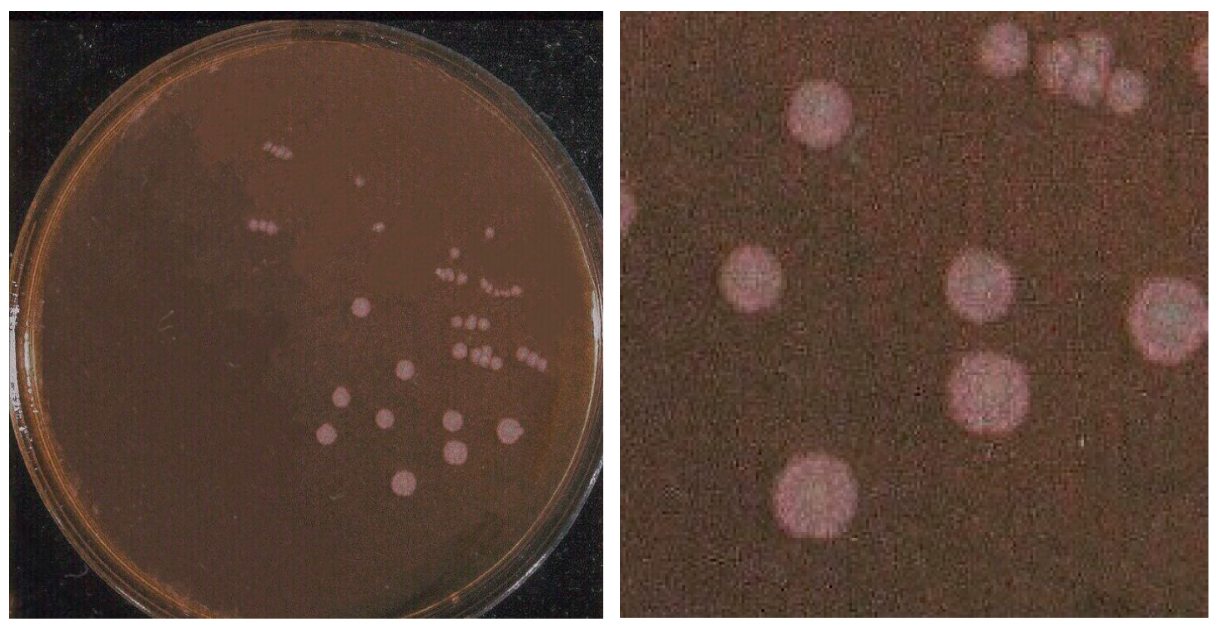

Figure 15: The rupture figure of the microbial capsule under pressure.

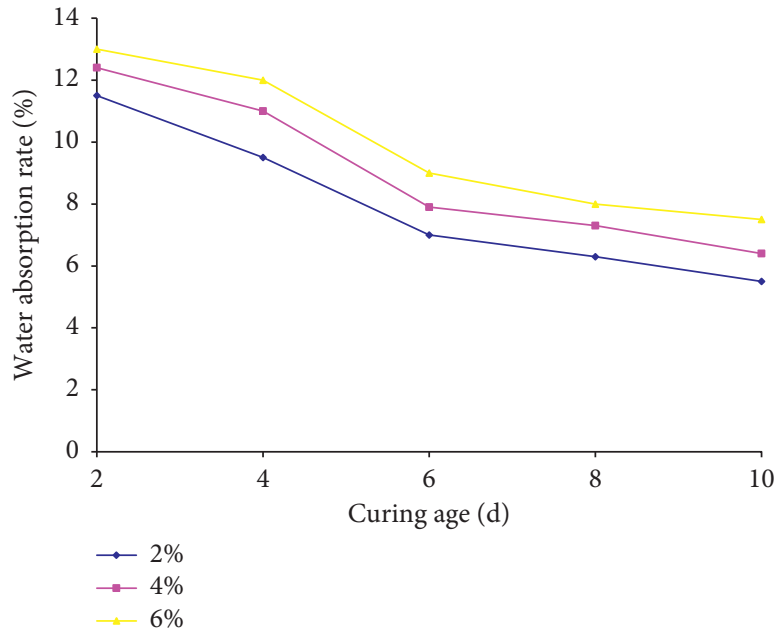

FIGURE 16: Water absorption ratio of test pieces under various microbial capsule amounts. 
TABLE 7: Comparison of compression strength under various curing ages.

\begin{tabular}{lccr}
\hline Repair agent & \multicolumn{3}{c}{ Strength (MPa) } \\
\\
\hline N/A & $3(\mathrm{~d})$ & $5(\mathrm{~d})$ & $7(\mathrm{~d})$ \\
Bacterial body & 2.311 & 2.432 & 2.517 \\
Microbial capsule & 2.436 & 2.317 & 2.336 \\
\hline
\end{tabular}

\section{Conclusion}

In this paper, microbial capsules were prepared by using Bacillus pasteurii coated with epoxy resin E-51, and the optimal conditions for preparing microbial capsules were determined according to single-factor experiments. We conclude that

(1) The optimum process conditions for microbial capsules are $1: 3$ in the core-wall ratio, $50^{\circ} \mathrm{C}$ in the reaction temperature, $40 \mathrm{~min}$ in the reaction time, and a stirring rate of $300 \mathrm{rpm}$.

(2) Epoxy resin E-51 was coated on the surface of the core material particles to form an epoxy resin E-51 coated microbial capsule. The test piece mixed with microbial capsules was cured for a certain period after predamage. Its compressive strength was enhanced, indicating that the microbial capsules played a repairing role.

(3) Microbial capsules have excellent waterproofness and high storage stability. The microbial capsules are embedded in the concrete to achieve mechanical triggering properties and thus rupture. The spore survival rate in the microbial capsules is $66.7 \%$. The wall material is biocompatible with the core material.

\section{Data Availability}

The data and models generated or used during the study are available from the corresponding author by request.

\section{Conflicts of Interest}

The authors declare that they have no conflicts of interest.

\section{Acknowledgments}

This work was funded by the National Natural Science Foundation of China (Grant nos. 51904032, 51874192, and 41807211), Research Fund of Binzhou University (Grant no. BZXYLG1914), Open Fund of Key Laboratory of Mine Disaster Prevention and Control (Grant no. MDPC201920), Natural Science Foundation of Shandong Province (Grant no. ZR2019MEE084), and SDUST Research Fund (Grant no. 2018TDJH102).

\section{References}

[1] S. Joshi, S. Goyal, A. Mukherjee, and M. S. Reddy, "Microbial healing of cracks in concrete: a review," Journal of Industrial Microbiology and Biotechnology, vol. 44, no. 11, pp. 1511-1525, 2017.
[2] M. Wu, X. Hu, Q. Zhang, D. Xue, and Y. Zhao, "Growth environment optimization for inducing bacterial mineralization and its application in concrete healing," Construction and Building Materials, vol. 209, pp. 631-643, 2019.

[3] M. Seifan, A. K. Samani, and A. Berenjian, "Bioconcrete: next generation of self-healing concrete," Applied Microbiology and Biotechnology, vol. 100, no. 6, pp. 2591-2602, 2016.

[4] J. Wang, A. Mignon, D. Snoeck et al., "Application of modified-alginate encapsulated carbonate producing bacteria in concrete: a promising strategy for crack self-healing," Frontiers in Microbiology, vol. 6, p. 1088, 2015.

[5] S. Bhaskar, K. M. Anwar Hossain, M. Lachemi, G. Wolfaardt, M. Otini Kroukamp, and M. O. Kroukamp, "Effect of selfhealing on strength and durability of zeolite-immobilized bacterial cementitious mortar composites," Cement and Concrete Composites, vol. 82, pp. 23-33, 2017.

[6] J. Hommel, E. Lauchnor, A. Phillips et al., "A revised model for microbially induced calcite precipitation: improvements and new insights based on recent experiments," Water Resources Research, vol. 51, no. 5, pp. 3695-3715, 2015.

[7] M. Seifan, A. K. Samani, and A. Berenjian, "Induced calcium carbonate precipitation using Bacillus species," Applied Microbiology and Biotechnology, vol. 100, no. 23, pp. 9895-9906, 2016.

[8] J. Wang, H. M. Jonkers, N. Boon, and N. De Belie, "Bacillus sphaericus LMG 22257 is physiologically suitable for selfhealing concrete," Applied Microbiology and Biotechnology, vol. 101, no. 12, pp. 5101-5114, 2017.

[9] J. Y. Wang, H. Soens, W. Verstraete, and N. De Belie, "Selfhealing concrete by use of microencapsulated bacterial spores," Cement and Concrete Research, vol. 56, no. 2, pp. 139-152, 2014

[10] S. Rathore, P. W. S. Heng, and L. W. Chan, "Feasibility study on microencapsulation of anaerobic Clostridium acetobutylicum ATCC 824 by emulsification method for application in biobutanol production," Journal of Microencapsulation, vol. 31, no. 5, pp. 469-478, 2014.

[11] X. Wu, S. Zhao, J. Zhang, P. Wu, and C. Peng, "Encapsulation of EV71-specific IgY antibodies by multilayer polypeptide microcapsules and its sustained release for inhibiting enterovirus 71 replication," RSC Advances, vol. 4, no. 28, pp. 14603-14612, 2014.

[12] M. G. Sierra-Beltran, H. M. Jonkers, and E. Schlangen, "Characterization of sustainable bio-based mortar for concrete repair," Construction and Building Materials, vol. 67, pp. 344-352, 2014.

[13] Q. Zhang, G. Zhou, Y. Hu et al., "Risk evaluation and analysis of a gas tank explosion based on a vapor cloud explosion model: a case study," Engineering Failure Analysis, vol. 101, pp. 22-35, 2019.

[14] D. Xu, W. Chen, and X. Fan, "Experimental investigation of particle size effect on the self-healing performance of microcapsule for cemented coral sand," Construction and Building Materials, vol. 256, Article ID 119343, 2020. 
[15] P. Singh, I. Kaur, and N. Singh, "A review of different bacteria carriers used in self-healing mechanism," Materials Today: Proceedings, vol. 32, pp. 955-960, 2020.

[16] X. Wang, Y. Huang, Y. Huang et al., "Laboratory and field study on the performance of microcapsule-based self-healing concrete in tunnel engineering," Construction and Building Materials, vol. 220, pp. 90-101, 2019.

[17] A. Al-Tabbaa, C. Litina, P. Giannaros, A. Kanellopoulos, and L. Souza, "First UK field application and performance of microcapsule-based self-healing concrete," Construction and Building Materials, vol. 208, pp. 669-685, 2019.

[18] S. Han, E. K. Choi, W. Park, C. Yi, and N. Chung, "Effectiveness of expanded clay as a bacteria carrier for self-healing concrete," Applied Biological Chemistry, vol. 62, no. 1, p. 19, 2019.

[19] Z. Liu, "Preparation of microcapsule and its influence on selfhealing property of asphalt," Petroleum Science and Technology, vol. 37, no. 9, pp. 1025-1032, 2019.

[20] A. Mohamed, T. Sharma, A. Heath, C. Richard, and K. Paine, "Application of expanded perlite encapsulated bacteria and growth media for self-healing concrete," Construction and Building Materials, vol. 160, pp. 610-619, 2018.

[21] M. Tripathi, D. K. Rahamtullah, D. Kumar, C. Rajagopal, and P. Kumar Roy, "Influence of microcapsule shell material on the mechanical behavior of epoxy composites for self-healing applications," Journal of Applied Polymer Science, vol. 131, no. 15, Article ID 40572, 2014.

[22] H. Singh and R. Gupta, "Cellulose fiber as bacteria-carrier in mortar Self-healing quantification using UPV," Journal of Building Engineering, vol. 28, pp. 1-14, Article ID 101090, 2020.

[23] S. Shahid, M. A. Aslam, S. Ali, M. Zameer, and M. Faisal, "Selfhealing of cracks in concrete using Bacillus strains encapsulated in sodium alginate beads," Chemistry, vol. 5, no. 1, pp. 312-323, 2020.

[24] M. Wu, X. Hu, Z. Hu, Y. Zhao, W. Cheng, and W. Lu, “Twocomponent polyurethane healing system: effect of different accelerators and capsules on the healing efficiency of dynamic concrete cracks," Construction and Building Materials, vol. 227, Article ID 116700, 2019.

[25] W. Mingyue, H. Xiangming, Z. Qian, L. Wei, Z. Yanyun, and $\mathrm{H}$. Zhenglong, "Study on preparation and properties of environmentally-friendly dust suppressant with semi-interpenetrating network structure," Journal of Cleaner Production, vol. 259, Article ID 120870, 2020.

[26] Z.-X. Hu, X.-M. Hu, W.-M. Cheng, Y.-Y. Zhao, and M.-Y. Wu, "Performance optimization of one-component polyurethane healing agent for self-healing concrete," Construction and Building Materials, vol. 179, pp. 151-159, 2018.

[27] M. Al-Ansari, A. G. Abu-Taqa, M. M. Hassan, A. Senouci, and J. Milla, "Performance of modified self-healing concrete with calcium nitrate microencapsulation," Construction and Building Materials, vol. 149, pp. 525-534, 2017.

[28] L. Souza and A. Al-Tabbaa, "Microfluidic fabrication of microcapsules tailored for self-healing in cementitious materials," Construction and Building Materials, vol. 184, pp. 713-722, 2018.

[29] W. Cheng, Study on the Performance of Micro Encapsulated Microbe Self Repairing concrete Cracks, Shenzhen University, Shenzhen, China, 2016.

[30] J. Y. Wang, D. Snoeck, S. Van Vlierberghe, W. Verstraete, and N. De Belie, "Application of hydrogel encapsulated carbonate precipitating bacteria for approaching a realistic self-healing in concrete," Construction and Building Materials, vol. 68, pp. 110-119, 2014.

[31] J. Wang, K. Van Tittelboom, N. De Belie, and W. Verstraete, "Use of silica gel or polyurethane immobilized bacteria for self-healing concrete," Construction and Building Materials, vol. 26, no. 1, pp. 532-540, 2012.

[32] K. Van Tittelboom, N. De Belie, W. De Muynck, and W. Verstraete, "Use of bacteria to repair cracks in concrete," Cement and Concrete Research, vol. 40, no. 1, pp. 157-166, 2010.

[33] W. Cheng, X. Hu, J. Xie, and Y. Zhao, "An intelligent gel designed to control the spontaneous combustion of coal: fire prevention and extinguishing properties," Fuel, vol. 210, pp. 826-835, 2017.

[34] D. O. George and L. Jin, "Optimum conditions for microbial carbonate precipitation," Chemosphere, vol. 81, no. 9, pp. 1143-1148, 2010.

[35] E. Y. Cagatay, S. E. Hernandez, B. Nico, and D. B. Nele, "Enhanced crack closure performance of microbial mortar through nitrate reduction," Cement and Concrete Composites, vol. 70, pp. 159-170, 2016. 